\title{
ФОРМИРОВАНИЕ СВЯЗНОГО ВЫСКАЗЫВАНИЯ У ДОШКОЛЬНИКОВ С РЕЧЕВЫМИ НАРУШЕНИЯМИ СРЕДСТВАМИ АРТ-ПЕДАГОГИЧЕСКИХ ТЕХНОЛОГИЙ
}

\section{FORMATION OF A CONNECTED EXPRESSION IN PRESCHOOLERS WITH SPEECH DISORDERS BY ART-PEDAGOGICAL TECHNOLOGIES \\ O. Bobkova \\ A. Gamayunova}

Summary: The article deals with the problem of increasing the efficiency of speech therapist's work in the formation of a coherent statement in preschoolers with speech disorders. The authors describe the main directions and organization of work on the formation of a coherent statement in older preschoolers with a general underdevelopment of speech by means of art-pedagogical technologies.

Keywords: formation, coherent speech, preschoolers, speech impairment, art pedagogy, technology.
$\mathrm{B}$ ажнейшим условием успешности социализации дошкольника, основой его дальнейшего обучения в школе является высокий уровень его речевого развития и, в частности, овладение связной речью. Достижение в дошкольном возрасте уровня развития связной речи, соответствующего коммуникативным потребностям ребенка, обозначается исследователями как важнейшая педагогическая проблема.

Недостатки речевого развития и связанные с ними проблемы вхождения в социум, свойственные детям с общим недоразвитием речи, обусловливают особую значимость поиска эффективных методов и приемов формирования связного высказывания у этой категории дошкольников.

Изучением данной проблемы занимались такие ученые, как Н.Е. Арбекова, Е.Ф. Архипова, Т.П. Бессонова, В.П. Глухов, И.А. Зимняя, Т.П. Колодяжная, М.Р. Львов, Л.Д. Мали, В.Н. Поникарова, Т.Г. Рамзаева, Е.М. Струнина, Т.А. Ткаченко, Т.В. Туманова, О.С. Ушакова, Т.Б. Филичева, Н.С.
Бобкова Ольга Валерьевна

К.п.н., дочент, Мордовский государственный педагогический университет имени М.Е. Евсевьева

(2. Саранск)

bobkova7@yandex.ru

Гамаюнова Антонина Николаевна

К.п.н., дочент, Мордовский государственный педагогический университет имени М.Е. Евсевьева

(2. Саранск)

gamaenova@yandex.ru

Аннотация: В статье рассматривается проблема повышения эффективности работы логопеда по формирования связного высказывания у дошкольников с речевыми нарушениями. Авторами описаны основные направления и организация работы по формированию связного высказывания у старших дошкольников с общим недоразвитием речи средствами арт-педагогических технологий.

Ключевые слова: формирование, связное высказывание, дошкольники, нарушение речи, арт-педагогика, технологии.

Худенцова, С.Н. Шаховская, А.В. Ястребова и др.

Исследователями отмечается, что эффективность коррекционно-логопедической работы с дошкольниками с общим недоразвитием речи в значительной степени обеспечивается комплексным характером воздействия. Интеграция логопедических занятий и различных видов продуктивной деятельности (рисование, конструирование и др.) обозначается учеными как актуальное и перспективное направление в решении указанной проблемы.

Вместе с тем, анализ имеющихся исследований демонстрирует недостаточную разработанность практических вопросов использования различных видов продуктивной деятельности в процессе формирования связного высказывания у детей с речевыми нарушениями на логопедических занятиях в детском саду комбинированного вида. Данное противоречие определяет актуальность проведенного нами исследования.

\footnotetext{
1 «Исследование выполнено в рамках гранта на проведение научно-исследовательских работ по приоритетным направлениям научной деятельности вузов-партнеров по сетевому взаимодействию (Южно-Уральский государственный гуманитарнопедагогический университет и Мордовский государственный педагогический университет им. М.Е. Евсевьева) по теме: «Пихолого-педагогическое сопровождение детей с ограниченными возможностями здоровья средствами арт-педагогических технологий в условиях инклюзивной практики»».
} 
Р.И. Лалаева и Н.В. Серебрякова характеризуют дошкольников с тяжелыми нарушениями речи как особую группу детей с отклонениями в развитии. По указанию авторов, у детей этой категории сохранен слух, первично не нарушен интеллект, но есть значительные речевые дефекты, влияющие на становление психики [5].

Р.Е. Левина определяет общее недоразвитие речи как нарушение, затрагивающее различные компоненты речи: звукопроизношение (снижение внятности речи, дефекты звуков), фонематический слух (недостаточное овладение звуковым составом слова), лексико-грамматический строй (бедность словарного запаса, неумение согласовывать слова в предложении) [6].

Данные ряда исследователей (В.П. Глухов, Н.С. Жукова, Е.М. Мастюкова, Т.Б. Филичева, Р.И. Лалаева, Н.В. Серебрякова, Р.Е. Левина, Г.В. Чиркина и др.) показывают, что у детей с общим недоразвитием речи значительно хуже, чем у нормально говорящих сверстников, сформированы зрительное восприятие, пространственные представления, внимание и память. Наличие общего недоразвития речи приводит к стойким нарушениям деятельности общения и создает серьезные проблемы на пути их развития и обучения.

В сентябре 2020 г. нами было проведено экспериментальное изучение особенностей развития связной речи старших дошкольников с общим недоразвитием речи, являющихся воспитанниками МДОУ «Детский сад № 70 комбинированного вида» г. о. Саранск. В констатирующем эксперименте принимали участие 11 дошкольников в возрасте 5-6 лет с логопедическим заключением «Общее недоразвитие речи, III уровень речевого развития». Эксперимент проводился в индивидуальной форме. Испытуемым было предложено выполнить 3 экспериментальных задания.

Задание 1 - выявление умения последовательно описать предмет, самостоятельно составляя связное высказывание: на листе бумаги перед испытуемым из плоскостных геометрических фигур разного цвета выкладывалось изображение грузовой машины; ребенку предлагалось рассмотреть изображение и описать его.

Задание 2 - выявление умения последовательно описывать сюжетное изображение: ребенку предлагалась для рассматривания сюжетная картинка (подвижная аппликация), составленная из геометрических фигур; испытуемому предлагалось рассмотреть изображение и описать его.

Задание 3 - выявление умения последовательно рассказывать о собственной деятельности: экспериментатор просил дошкольника выложить на листке бумаги картинку по предложенному образцу - для выполнения задания испытуемому предлагался набор геометрических фигур из цветного картона; дошкольнику предлагалось рассказать о том, как он выполнял аппликацию.

Результаты выполнения экспериментальных заданий оценивались по следующим критериям: 1) умение самостоятельно составлять предложения в соответствии с заданием; 2) распространенность составленных предложений; 3) уровень сформированности умения объединять предложения в связное, последовательное высказывание; 4) объем связного высказывания.

В соответствии с указанными критериями ответы дошкольников экспериментальной группы делились нами как правильные, частично правильные и неправильные.

Анализ результатов проведенного констатирующего эксперимента показал, что у дошкольников экспериментальной группы наблюдается низкий уровень сформированности связной речи. Это выражается в следующих качественных характеристиках: трудностях самостоятельного составления предложений, соответствующих содержанию задания. Большинство детей использует нераспространенные предложения, состоящие из подлежащего и сказуемого, выраженных существительным и глаголом. Дошкольниками редко используются предложения, включающие прилагательные и наречия. Это делает их связные высказывания очень бедными. В них и мало отражаются свойства и характерные особенности предметов и явлений, их состояние.

Недостаточный уровень сформированности связной речи детей так же выражается в затруднениях при самостоятельном построении высказывания: дети затрудняются самостоятельно выстроить логическую последовательность предложений для последовательного описания объекта или ситуации. Особенно сложным для них является последовательный рассказ о собственной практической (изобразительной) деятельности. Высказывания детей имеют непоследовательный, отрывочный характер. Это демонстрирует недостаточное развитие регулирующей функции речи у детей, что так же затрудняет для них планирование практической продуктивной деятельности.

Результаты выполнения заданий показали, что самостоятельные высказывания детей невелики по объему и чаще ограничиваются 4-5 предложениями, расположенными в произвольном порядке.

Как указывает Л.С. Выготский, находясь в тесном единстве с другими познавательными процессами, речь зарождается и совершенствуется в результате деятельности. Выполняя различные действия, ребенок вступает 
в непосредственный контакт с окружающей действительностью, приобретая при этом определенный практический опыт, который имеет первостепенное значение для развития его мышления и речи [3].

Отечественные и зарубежные исследователи указывают, что художественно-творческая деятельность играет важную роль в воспитании, развитии и обучении каждого ребенка. Она положительно влияет на сенсорное развитие, формирование мотивационной стороны деятельности. Занятия разными видами художественной деятельности способствуют интеграции перцептивных, мнестических и мыслительных процессов, развивают тонкую моторику рук и положительно сказываются на становлении речевой деятельности.

По определению Н.С. Баряевой, Н.Н. Ванинцевой, К.А. Воронкиной, Н.Э. Куликовской, Ю.А. Талавера, артпедагогические технологии - это творческое конструирование средствами искусства эмоционально значимых для человека творческих действий (взаимодействий), система педагогических методов, реализация которых способствует развитию познавательных процессов, активному формированию личности, развитию духов-нонравственной культуры и потребности в самосовершенствовании.

К числу арт-педагогических технологий ученые относят: визуальные арт-технологии (рисунок, лепку, аппликацию, коллаж, песочную арт-технологию); музыкальную арт-технологию (игру на музыкальных инструментах, пение и др.); драматехнологию (театрализованные игры, постановки); нарративную арт-технологию (связанную с созданием текстов) и др. [1].

Арт-педагогические технологии позволяют формировать и совершенствовать программирующую, регулирующую, коммуникативную функцию речи, что обусловливает большой потенциал их применения в коррекционно-развивающей работы с детьми с речевыми нарушениями [4].

Изобразительная деятельность благоприятна для формирования речи еще и потому, что при ее осуществлении легко можно создавать проблемные ситуации, способствующие повышению речевой активности детей. Проблемные ситуации формируют коммуникативную направленность речи [2].

Совершенствование речи детей средствами различных видов деятельности лежит в основе принципа коммуникативно-действенного подхода, широко применяемого в настоящее время в системе общего и специального образования [8].
В сентябре - ноябре 2020 г. нами был проведен формирующий эксперимент в МДОУ «Детский сад № 70 комбинированного вида» г.о. Саранск. В нем принимали участие 11 дошкольников с логопедическим заключением «Общее недоразвитие речи, III уровень речевого развития», ранее обследованных нами по методике констатирующего эксперимента.

Формирующий эксперимент проводился на логопедических занятиях. В каждое занятие были включены задания, связанные с выполнением художественной аппликации по следующим темам: «Букет» (предметная аппликация), «Платок с осенним узором» (декоративная аппликация), «Осень пришла» (сюжетная аппликация), «Узор для полотенца» (декоративная аппликация), «Встречаем осень» (декоративная аппликация), «Осенняя прогулка» (сюжетная аппликация). Содержание заданий по выполнению аппликации было определено нами на основе «Программы воспитания и обучения дошкольников с тяжелыми нарушениями речи», разработанной Л.Б. Баряевой, О.П. Гаврилушкиной, Г.Г. Голубевой и другими авторами [7].

Всего в ходе эксперимента нами было проведено 11 фронтальных логопедических занятий (с периодичностью 1 раз в неделю) с использованием данного вида художественно-творческой деятельности. Так как экспериментальное обучение осуществлялось осенью, занятия проводились нами по лексической теме «Времена года. Осень». В ходе каждого занятия мы опирались на результаты работы, проведенной совместно с воспитателями группы за неделю по каждой лексической теме, в том числе, на занятиях по изобразительной деятельности.

Работа проводилась нами по следующим направлениям: 1) работа над лексикой (обогащение и активизация словарного запаса по предложенной теме); 2) формирование умения составлять распространенные предложения по предложенной теме; 3) формирование умения последовательно сопровождать собственные продуктивные действия речью; 4) формирование умения последовательно рассказывать о выполненной работе.

Логопедические занятия с использованием артпедагогических технологий (изобразительная деятельность - аппликация) имели следующую структуру: 1) подготовительная часть (организационный момент, вводная беседа, подготовительные игры и тренировочные упражнения игрового характера, которые помогали логопеду настроить детей на работу, активизировать их словарный запас и внимание, вспомнить и закрепить пройденный на предыдущих занятиях речевой материал.); 2) основная часть (введение в тему занятия, мотивация детей на включение предстоящую деятельность при помощи проблемной или игровой ситуации, словарная 
работа, анализ образца аппликации или обсуждение темы (для сюжетных аппликаций), анализ условий выполнения работы, планирование предстоящей работы, практическая работа по выполнению аппликации, физкультурная пауза, составление описательного рассказа, отражающего содержание и последовательность выполненной работы); 3) заключительная часть (организация выставки выполненных аппликаций, представление дошкольниками рассказов о работе, совместный анализ логопедом и детьми рассказов детей - их полноты, последовательности, смыслового соответствия логике выполнения художественной работы и лексической теме, подведение итогов занятия, организованное окончание занятия).

С целью формирования связного высказывания у старших дошкольников с общим недоразвитием речи нами была разработана система игровых заданий, которые включались нами в логопедические занятия с использованием арт-педагогических технологий (аппликации).

Подготовительная часть каждого занятия включала вводную беседу с дошкольниками по теме «Осень пришла». Проводившиеся беседы были направлены на выявление знаний детей о данном времени года, а также их представлений о приметах осени. Содержание вопросов было таким, чтобы в своих ответах дети использовали не только существительные и глаголы, но также прилагательные и наречия для характеристики свойств объектов.

Для актуализации и уточнения представлений старших дошкольников, активизации и обогащения их словаря по лексической теме «Осень пришла», на данном этапе нами использовались соответствующие средства наглядности и упражнения игрового характера. Демонстрируемые дидактические средства и изображения наглядно представляли особенности природных объектов и явлений окружающей действительности, характерные для осени. Для активизации мышления дошкольников в процессе демонстрации и беседы организовывалось сравнение данных дидактических материалов с другими картинками, представляющими приметы лета.

В рамках работы по первому направлению, с целью активизации и обогащения словаря дошкольников по лексической теме «Осень пришла» на этапе подготовки к выполнению аппликации нами использовались упражнения игрового характера: «Кто больше?», «Что не так?», «Рассказчики», «Скажи по-другому», «Поможем кукле». В качестве примера приведем описание одного из игровых упражнений.

Упражнение «Что не так?»
Цель: активизация и обогащение лексики по теме «Осень пришла».

Содержание. Детям предлагается рассмотреть сюжетную картинку на тему «Осень» с изображением осеннего дня. Педагог предлагает детям внимательно слушать предложения, которые он будет произносить, и определить, в какой из фраз содержится ошибка (например: осенью дети загорают, купаются, носят легкую одежду; осенью под ногами шуршат сухие разноцветные листья). Ребенок, который быстрее определил ошибку и смог исправить ее - сказать правильно, получает картинку-сюрприз.

Оборудование: сюжетная картинка-аппликация на тему «Осень».

Использование данных упражнений игрового характера позволило нам организовывать беседу на каждом занятии с опорой на наглядный материал. Также их применение обеспечивало подготовку дошкольников к анализу образца и обсуждению содержания аппликаций, которые детям предстояло выполнить на занятии, к планированию практических действий.

Работа по второму направлению осуществлялась нами на этапе анализа образца аппликации в основной части логопедического занятия. Упражнения игрового характера, которые использовались на данном этапе, помогали дошкольникам составлять самостоятельное связное высказывание - характеристику образца для предметной аппликации или описание варианта содержания сюжетной аппликации. С этой целью применялись следующие упражнения: «Художник», «Цепочка», «Лучший рассказчик», «Друг за другом» и др. Приведем описание одного из игровых упражнений.

\section{Упражнение «Друг за другом»}

Цель: развитие умения составлять распространенные предложения по предложенной лексической теме.

Содержание. Педагог предлагает дошкольникам составить на доске план анализа объекта-образца из рисунков-символов, обозначающих свойства объектов. Дети по очереди подходят к столу, выбирают нужный пункт плана и размещают карточку по порядку на доске. Затем он показывает детям образец аппликации и предлагает им описать его по составленному плану. Каждый ребенок составляет 1 предложение по пункту плана. Подобным образом дошкольники друг за другом дают характеристику аппликации-образца.

Оборудование: карточки с символическим обозначением пунктов плана, аппликация-образец. 
Особое внимание обращалось нами на обсуждение вариантов содержания сюжетных аппликаций. На занятиях по их изготовлению указанные игровые упражнения использовались нами как подготовительные к составлению детьми самостоятельных связных высказываний. После их выполнения дошкольникам предлагалось по составленному в ходе игры образцу подготовить описание собственной сюжетной аппликации по предложенной теме. При возникновении затруднений воспитанникам предоставлялась возможность выложить «подвижную» аппликацию из геометрических фигур большого формата на магнитной доске. Каждый из дошкольников мог подойти к доске и предложить свой вариант композиции. Далее с помощью педагога ребенок составлял описание придуманного сюжета.

В процессе выполнения игровых упражнений дошкольники составляли предложения, используя словаопределения для характеристики деталей аппликации, их величины, пространственного расположения и цвета. При возникновении затруднений (если дети не могли подобрать соответствующее определение) нами использовались различные вспомогательные материалы.

Для выполнения данных упражнений детям предлагались дидактические материалы (наборы геометрических форм разного цвета и размера, демонстрационные карточки разного цвета, графические планы для составления связного высказывания - описания образца аппликации), серия сюжетных картинок на тему «Осень пришла». При этом структура графических планов была определена нами с учетом последовательности анализа образца, так, чтобы связное высказывание, выстроенное детьми на их основе, соответствовало логической схеме этого процесса.

Работа по третьему направлению (формирование умения последовательно выполнять аппликацию и сопровождать свои действия речью) проводилась нами на этапе планирования выполнения аппликации и в ходе ее изготовления детьми. На этапе планирования изготовления аппликации дошкольникам предлагалось предварительно составить предметно-операционный план, сопровождая свои действия речью. Дошкольники при помощи логопеда определяли последовательность выполнения аппликации - каждый этап работы проговаривался и воспроизводился с помощью карточек с изображением соответствующей операции на доске. На последующих занятиях дети сами создавали «план» из карточек, выбирая их из предложенного набора и выстраивая правильную последовательность на доске. Эта деятельность выполнялась коллективно - дошкольники по очереди подходили к столу с лежащими карточками, выбирали изображение соответствующего этапа выполнения аппликации, проговаривали его и размещали на доске. По каждому этапу дети с помощью педагога составляли 1-2 предложения. После того, как на доске выстраивался полный план выполнения аппликации, дети, опираясь на него, повторяли полностью всю последовательность работы. При этом логопед обращал внимание дошкольников на последовательность этапов работы, помогал сформулировать предложения, выбрать правильные грамматические формы для установления связи предложений между собой.

После того, как процесс выполнения аппликации был спланирован, дошкольники приступали к выполнению работы. Поделка выполнялась детьми поэтапно, в соответствии с пунктами плана. При переходе от этапа к этапу педагог задавал детям вопросы и просил еще раз проговорить, что они делали на предыдущем этапе, что будут делать сейчас, а также, каким будет следующее действие. Вопросы в процессе работы задавались всем дошкольникам, что также способствовало совершенствованию регулирующей функции печи, формированию у них умений самоконтроля в процессе практической деятельности.

Работа по четвертому направлению (формирование умения последовательно рассказывать о выполненных действиях) осуществлялась на этапе анализа выполненных работ и подведения итогов занятия. На доске нами организовывалась выставка выполненных аппликаций. Детям давалось время на их рассматривание. Далее логопедом организовывалась беседа с дошкольниками. С опорой на вопросы педагога дети сравнивали аппликации между собой и давали их характеристику. При этом им предлагалось отвечать полным ответом, используя слова-определения, наречия, которые повторялись на занятии.

Подведение итогов занятия предполагало составление детьми небольшого отчета о процессе выполнения аппликации. Они припоминали последовательность действий и составляли 2-3 предложения по каждому этапу работы. Особое внимание на данном этапе нами обращалось на то, чтобы дети правильно использовали глаголы при составлении словосочетаний и предложений со словами-определениями.

На последующих этапах работы дошкольникам предлагалось составить рассказ о выполненных действиях без опоры на наглядный материал.

С целью выявления эффективности проведенного экспериментального обучения, в декабре 2020 года нами был проведен сравнительный контрольный эксперимент. В нем принимали участие 11 детей, участвовавших в формирующем эксперименте, а также 11 дошкольников 5-6 лет - воспитанников МДОУ «Детский сад № 86 
комбинированного вида» г. о. Саранск, с логопедическим заключением «Общее недоразвитие речи, III уровень речевого развития» - в качестве контрольной группы.

Детям обеих групп были предложены 2 экспериментальных задания, направленных на выявление уровня сформированности умения последовательно рассказывать о собственных действиях, а также о содержании выполняемых аппликаций. Результаты выполнения заданий контрольного эксперимента оценивались нами в соответствии с критериями, установленными в ходе констатирующего эксперимента.

Качественный сравнительный анализ полученных результатов позволил нам сделать ряд выводов относительно эффективности использования артпедагогических технологий (аппликация) с целью раз- вития связной речи дошкольников на логопедических занятиях.

Результаты проведенного сравнительного контрольного эксперимента показали, что у дошкольников экспериментальной группы на более высоком уровне сформировано умение описывать последовательность собственных изобразительных действий. Их отличает также более высокий уровень сформированности умения вести описательное повествование. Самостоятельные высказывания детей были невелики по объему, но их отличала большая последовательность и логичность, чем у дошкольников экспериментальной группы. Это, по нашему мнению, свидетельствует об эффективности использования арт-педагогических технологий (аппликация) с целью развития связной речи дошкольников с общим недоразвитием речи на логопедических занятиях.

\section{ЛИТЕРАТУРА}

1. Арт-технологии в коррекционно-развивающей работе с детьми с ограниченными возможностями здоровья: учебно-методическое пособие для педагогоВ, психологов и родителей / Н.С. Баряева, Н.Н. Ванинцева, К.А. Воронкина [и др.]; Российский государственный педагогический университет им. А.И. Герцена. - Санкт-Петербург: Изд-во РГПУ им. А.И. Герцена, 2017. - 74,

2. Бобкова, О.В. Общекультурное развитие школьников как условие успешности образовательной инклюзии / О.В. Бобкова // Гуманитарные науки и образование. - 2013. - № 1 (13). - С. 49-53.

3. Выготский, Л.С. Воображение и творчество в детском возрасте / Л.С. Выготский. - 3-е изд. - М. : Просвещение, 2009. -95 с.

4. Кузьмина, Н.Н. Моделирование артпедагогических технологий в процессе психолого-педагогического сопровождения детей в условиях инклюзивного образования / Н.Н. Кузьмина // Гуманитарные науки и образование. - 2014. - № 1 (17). - С. 46-50.

5. Лалаева, Р.И. Формирование лексики и грамматического строя у дошкольников с общим недоразвитием речи / Р.И. Лалаева, Н.В. Серебрякова. - СПб.: KAP0, 2011. $-317 \mathrm{c}$.

6. Левина, Р. Е. Нарушения речи и письма у детей: избранные труды / Р.Е. Левина, Г.В. Чиркина / ред.-сост. Г.В. Чиркина, П.Б. Шошин. - 2-е изд. - М. : Просвещение, 2013. - 362 с.

7. Программа воспитания и обучения дошкольников с тяжелыми нарушениями речи / под ред. Л.Б. Баряевой, 0.П. Гаврилушкиной, Г.Г. Голубевой; под ред. проф. Л.В. Лопатиной. - СПб.: ЦДК проф. Л. Б. Баряевой, 2009. - 415 с.

8. Рябова, Н.В. Мониторинг уровня сформированности универсальных учебных действий младших школьников / Н.В. Рябова, Е.А. Демидова, О.В. Терлецкая// Гуманитарные науки и образование. -2018. - Том 9. - № 3. - С. 113-120.

(c) Бобкова Ольга Валерьевна (bobkova7@yandex.ru), Гамаюнова Антонина Николаевна (gamaenova@yandex.ru).

Журнал «Современная наука: актуальные проблемы теории и практики» 